\title{
이상향을 향한 나침반: 인도적 원칙에 관한 고찰
}

목 차

I. 서론

II. 인도적 원칙의 기원

1. 국제인도법과 인도적 원칙

2. 인도적 원칙의 발전

III. 인도적 원칙 분석

1. 인도의 원칙

2. 공평의 원칙

3. 중립의 원칙

4. 독립의 원칙

5. 원칙간의 상관성

IV. 인도적 원칙에의 도전과 유효성

1. 인도적 원칙에의 도전

2. 인도적 원칙의 유효성

V. 결론

\section{I. 서론}

인도(humanity), 공평(impartiality), 중립(neutrality), 독립(independence)은 국 제적으로 인도적 지원 활동을 수행하는 단체들이 채택하고 있는 4 대 활동 원칙이다. 인도는 그 어디에서 발견되든지 인간의 고통은 경감되어야 하며 생명은 구조되어야 한다는 원칙이며, 공평은 인종, 성별, 국적, 종교, 계층, 정치적 성향 등에 관계없이 
지원이 가장 필요한 사람에게 가장 먼저 전달되어야 함을 의미한다. 중립은 지원활 동을 수행함에 있어 분쟁 당사자들의 편을 들지 않아야 한다는 원칙이며 독립은 인 도적 지원이 정치적, 경제적, 군사적 등의 목적에 구속되지 않는 것을 뜻한다. 인도 적 원칙은 인도적 지원 활동에 있어서 적용되는 독특한 철학 원칙으로서 군사원조 (military aid)나 개발 원조(development assistance)등의 다른 형태의 원조와 인도 적 지원을 구분 짓는 중요한 기준으로 작용하고 있다.

인도적 원칙은 국제인도법에 그 유래를 두고 있으며, 현재는 유엔, 국제적십자운 동, 공여국정부, $\mathrm{NGO}$ 등 인도적 지원 단체의 정책 문서에 공식적으로 명시되어 있 다(장은하 2014a). 인도적 지원을 수행하는 국내 민간단체들도 이 원칙들이 반영되 어 있는 재난과 구호에 있어서의 국제적십자운동과 NGO의 행동강령(The Code of Conduct for the International Red Cross and Red Crescent Movement and NGOs in Disaster Relief, 이하 '적십자운동과 NGO의 행동강령')에 서명하고 스피 어 핸드북(The Sphere Handbook)을 활동의 기준으로 적극 채택하는 등 인도적 원 칙의 준수에 동의하고 있다.

이러한 광범위한 합의와 수용에도 불구하고 인도적 원칙의 적용은 국내외를 막론 하고 도전에 직면해 있다. 구조적인 차원으로는 냉전이후 분쟁의 양상 변화, 인도적 지원의 정치화, 미디어의 영향 등으로 인해 공평하고 중립적인 지원이 이루어지기 어려운 환경이 되었다. 개인적 혹은 조직적 차원으로는 인도적 원칙에 대한 인식 및 이해 부족, 업무에의 통합에 있어서의 어려움 등을 들 수 있다(국제개발협력 민간협 의회 2014:18; NRC 2012:39; Hilhorst and Schmeieman 2002). 필자가 인도적 지 원 관련 수업, 인도적 지원 종사자 교육, $\mathrm{KOICA}$ 관계자 면담 등을 통해 파악한 바 도 유사하다. 다차원의 교육과 현장 활동을 통해 인도적 원칙의 존재와 기본 정의에 관해서는 인지하고는 있으나, 원칙의 기원, 원칙 간의 상관성(혹은 차별성), 구체적 적용에 관한 정확하고도 심도 있는 이해가 필요한 것으로 관찰되었다.

본고는 이러한 배경과 필요성을 바탕으로 인도적 원칙에 대한 밀도 있는 해석을 제공하는 것을 그 목적으로 한다. 먼저 인도적 원칙의 유래와 발전 역사를 살펴봄으 로써 원칙이 형성된 역사적 맥락에 대한 이해를 도울 것이다. 다음으로 개별 원칙에 
대한 상세한 분석을 시도하며 구체적 적용을 검토할 것이다. 마지막으로 인도적 원 칙이 직면한 도전과 유효성을 고찰하고 향후 전망을 제시할 것이다. 본고를 통해 국 내외 현장에서 활동하는 단체들이 인도적 원칙에 대해 숙지하고, 지속적으로 참조함 으로써 활동의 방향을 설정하는 데에 도움이 되기를 바란다. 또한 정치적, 군사적인 개입으로 인해 오염되어 가고 있는 인도적 지원 현장에서 원칙에 기반을 둔 활동을 통해 인도적 이상향을 지켜나가는 데에 미약하나마 도움이 되고자 하는 바이다.

\section{II. 인도적 원칙의 기원}

제 I장

제II장

인도적 원칙은 두 가지 차원에서 이해될 수 있다. 먼저 전시를 배경으로 하는 국 제인도법적인 맥락으로, 전쟁을 수행하는 방식을 인도(humanity)라는 명분에 의해 제어하려는 시도를 말한다(Leader 2000: 2). 즉, 인도, 공평 등의 인도적 원칙은 전 쟁에서의 민간인을 보호하고 인도적 지원 전달을 용이케 함으로써 전쟁의 파괴적인 영향을 감소하는 역할을 한다. 또 다른 차원은, 분쟁 상황 및 자연재해에서의 인도적 지원에 있어서 적용되는 활동 원칙을 지칭한다(Mackintosh 2000; Hilhorst and Schmiemann 2002:491). 국제인도법 맥락에서의 인도적 원칙은 무력충돌 상황에만 적용되지만, 지원 활동의 지침으로서의 인도적 원칙은 자연재해를 비롯한 모든 인도 적 지원 활동의 근간이 되고 있다. 또한 국제적십자사가 국제인도법의 수호자 (guardian)로서의 역할을 담당하지만, 정부 간 기구이든 비정부기구이든, 현재 거의 대부분의 인도적 활동 기관은 이 원칙에 준하여 활동하고 있다(Ferris 2011:16). 본 고에서는 먼저 국제인도법상에서의 인도적 원칙을 검토하고, 이어서 지원 활동 기준 으로서 인도적 원칙에 논의의 초점을 맞출 것이다.

\section{1. 국제인도법과 인도적 원칙}

국제인도법은 무력충돌의 희생자를 보호하는 제네바법과 전투의 수단과 방법을 제 한하는 헤이그법으로 구성되어 있다. 제네바법은 전쟁 등의 국제 및 국내 무력충돌 시 적대행위 비가담자나 전투능력 상실자들을 보호하는 것을 그 목적으로 하며 헤이 그법은 무기사용 규제 등 전투수단과 방법을 제한함으로써 전쟁의 피해를 최소화한 다(대한적십자사 2012a:1). 제네바 4개의 협약에 공통으로 등장하는 제 3 조에서는 
“국제적십자위원회와 같은 공정한(impartial) 인도적 기구는 충돌당사국에 대하여 그 용역을 제공할 수 있다”라고 명시하며 전쟁 등의 무력충돌 상황에서 인도적 기관의 구호활동을 허용하고 있다.

인도, 공평, 중립, 독립의 인도적 원칙과 관련된 속성들은 국제인도법(International Humanitarian Law, IHL)의 곳곳에서 발견할 수 있다. 제네바협약과 추가의정서에서 “인도적(humanitarian)" “공정한(impartial)" “불리한 차별 없이(without adverse distinction)" 등의 인도적 원칙의 여러 속성들이 지속적으로 등장한다(MacKintosh 2000:7). 공통조항 제3조에서는 “전투력을 상실한 자와 적대행위에 능동적으로 참가 하지 아니하는 자는 모든 경우에 있어서 인종, 색, 종교 또는 신앙, 성별, 문벌이나 빈부 또는 기타의 유사한 기준에 근거한 '불리한 차별 없이 인도적'으로 대우하여야 한다”라고 명시한다. 이는 다음 장에서 보다 면밀히 검토할 공평의 속성에 대한 언급 이다. 같은 조항에서는 또한 이들에 대한 생명 및 신체에 대한 폭행(살인, 상해, 학 대, 고문), 인질로 삼는 일, 인간의 존엄성에 대한 침해를 금지할 것을 명시하고 있 으며, 법적보장 부여와 부상자 간호를 분명하게 밝히는 것을 통해 인도적인 처우가 실현될 수 있게 하고 있다. 이는 인간 그 자체로 존엄하게 대우받을 권리가 있다는 인도의 속성이 묘사된 조항이라고 할 수 있다.

또한 제네바 제 1 협약과 2 협약 12 조에서는 전투 비가담자에 대한 치료의 순서에 있어서 "우선권은 긴급한 의료상의 이유로서 허용되며, 부녀자는 여성이 당연히 받아 야 할 모든 고려로서 대우되어야 한다”고 언급하고 있다. 이는 지원의 필요가 더 크 고 위급한 피해자에게 우선적으로 지원될 것을 나타내는 것인데, 공평의 원칙 중 비 례성과 공평성의 속성에 해당하는 것이다. 이는 다음 장에서 더 상세히 살펴볼 것이 다. 나아가 포로의 대우에 관한 제3 협약 전반에서는 전쟁 포로는 항상 인도적으로 대우되어야 함을 강조한다. 특히 제 14 조에서는 "포로는 모든 경우에 있어서 그들의 신체와 명예를 존중받을 권리를 가진다”고 명시하고 있으며 이어서 “여자는 여성이 당연히 받아야 할 모든 고려로서 대우되며, 또한 여하한 경우에도 남자와 동등하게 대우되어야 한다”고 밝힘으로써 지원에 있어서 성별이 차별의 근거가 되지 않도록 하 고 있다. 이 또한 공평의 원칙에 부합하는 것이다. 
이와 같이 제네바 협약에서는 “인도적 원칙은 이것이다”라는 식의 조항을 포함하고 있지는 않지만, 비전투요원들의 구호활동을 위한 조건으로 공평, 비차별, 중립 등의 요소들이 제시되어 있다. 협약의 기저에 흐르는 철학적, 윤리적 기반들은 조항의 문 구에 드러나고 있는데, 여기에서 인도, 공평, 중립과 같은 속성들이 발견되고 있다 (Mackintosh 2000:13).

\section{2. 인도적 원칙의 발전}

인도적 지원 활동의 기준으로서의 인도적 원칙은 국제적십자운동의 원칙으로부터 직접적으로 유래하였다. ${ }^{1)}$ 국제적십자사운동은 그 시초부터 활동의 방향을 제시해 줄 수 있는 기본원칙의 수립이 요구되어 졌다. 1921년 제 10차 국제적십자회의에서 공 평성, 정치적, 종교적, 경제적 독립성, 적십자 운동의 보편성, 그리고 각국 적십자사 의 평등성이라는 적십자 기본 원칙이 결의됨으로써 공식적으로 규범화 되었다(대한적 십자사 2012: 4). 1965년 비엔나에서 열린 제 20회 국제적십자사회의에서는 인도 (humanity), 공평(impartiality), 중립(neutrality), 독립(independence), 봉사(voluntary service) 단일(unity) 그리고 보편(universality)의 일곱 가지 정신이 국제적십자운동의 7 대 원칙(Seven Fundamental Principles of International Red Cross and Red Crescent Movement)으로 채택되었다. 인도, 공평, 중립, 독립의 원칙은 국제적십자운 동의 정신과 존재이유 등의 근본적 성격을 나타내는 원칙이며, 자발적 봉사, 단일, 보편의 원칙은 국제적십자운동의 구조와 운영방식을 설명하는 원칙이다(대한적십자사 2012:2). 1986년 제25차 국제적십자회의에서는 적십자운동의 정관 전문에 기본원칙 을 포함시켜 적십자운동의 모든 구성기구들이 이 원칙을 존중하고 널리 알리도록 하 였다(대한적십자사 2012:5). 이는 국제적십자운동의 운영원칙으로서 현재까지 지속되 고 있다. ${ }^{2)}$

1) 국제적십자운동은 국제적십자위원회(ICRC), 국제적십자연맹(IFRC), 그리고 각국의 적 십자사의 세 구성기구로 이루어져 있다.

2) 삑테(Pictet)는 현 인도적 원칙의 모태인 국제인도법의 원칙과 바로 다음절에서 설명할 적십자운동의 기본원칙의 차이에 대해서 설명한다. 적십자사 기본원칙은 어느 때에나 사적인 기관으로서의 적십자의 활동을 고무하는 역할을 하지만, 국제인도법의 원칙은 공적인 속성을 가지고 있으며 전시에 적에 대한 특정 국가의 행동을 규제하는 데에 있 다고 밝힌다(Pictet 1979). 적십자운동의 기본원칙 중 4 개가 현 인도적 원칙으로 차용 되었음을 고려할 때, 삑테(Pictet)의 이러한 분석은 인도적 원칙과 국제인도법을 설명 
이후 인도, 공평, 중립, 독립의 세 원칙은 전 세계 인도적 구호 단체들의 운영 철 학으로 자리 잡게 되었다. 냉전종식 후 UN은 1991년 “유엔의 인도적 긴급지원 조율 강화(Strengthening of the Coordination of Humanitarian Emergency Assistance of the United Nations)"에 관한 결의안 46/182에서 국제 인도적 이슈 에 대한 적극적 개입 의사를 천명하였다. 이 결의안에서 $\mathrm{UN}$ 은 인도적 활동에 대해 정의를 내리고 인도, 공평, 중립의 세 원칙을 인도적 활동의 3 대 원칙으로 공식적으 로 표방하였다. 1994년에는 국제적십자사(ICRC)와 국제적십자연맹(IFRC)을 포함한 8 개의 주요 재난대응 국제 $\mathrm{NGO}$ 들이 "재난과 구호에 있어서의 국제적십자운동과 $\mathrm{NGO}$ 의 행동강령(The Code of Conduct for the International Red Cross and Red Crescent Movement and NGOs in Disaster Relief, 이하 '적십자운동과 NGO의 행 동강령')"에 서명하였다. ${ }^{3)}$ 이 강령의 처음 4 개 조항에서 인도, 공평, 중립, 독립의 4 개의 원칙의 준수를 촉구하고 있다. 특히 이 조항들은 인도적 원칙의 단순한 정의가 아닌, 상황별 적용을 구체적으로 풀어 제시함으로써 지원 단체들의 이해를 돕고 적 용이 용이하게 하였다. ${ }^{4)}$ 이 행동강령은 추후에 수립되는 기술적이고도 운영적인 지 침인 스피어 핸드북(The Sphere Handbook)의 윤리적 배경을 제공하게 된다.

1995년에는 수단생명선작전 수행규칙(Operation Lifeline Sudan Agreement on Ground Rules)의 도입부에 인도적 원칙이 명시됨으로서 실제 상황에 적용된 주요 사례가 되었다. 이 수행규칙에서는 복합적 위기 상황에서 인도적 원칙 준수를 통한 피해지역 접근 확보를 보장하였다.5) 2003년에는 유엔 총회 결의안 58/114에서 독립 의 원칙이 추가로 채택되었다. 같은 해 주요 공여국 정부들이 서명한 "인도적 공여의

하는 데에 있어서도 적용될 수 있다. 그러나 국제인도법과 적십자운동의 원칙 간에는 물론 연관성이 있다. 국제인도법은 적십자사의 이상에 그 기원을 두고 있으며 이 이상 은 적십자사의 발전을 촉진하여 왔다. 따라서 인도의 원칙, 비차별의 원칙 등의 특정 원칙은 양측에서 공통적으로 발견된다(Pictet 1979).

3) Caritas Internationalis, Catholic Relief Services, The International Federation of Red Cross and Red Crescent Societies, International Save the Children Alliance, Lutheran World Federation, Oxfam, The World Council of Churches, The International Committee of the Red Cross.

4) IFRC website http://www.ifrc.org/Docs/idrl//259EN.pdf(검색일: 2015.1.16)

5) PLM/OLS(Operation LIfeline Sudan) Agreement on Ground Rules, 1995. http://www. unicef.org/pathtraining/Documents/Session\%204\%20Humanitarian\%20Principles/Train er\%20Resources/4.11\%20SPLM\%200peration\%20Lifeline\%20Sudan\%20Ground\%20Rul es.doc(검색일: 2015.1.16). 
모범적 수행을 위한 23개의 원칙(The 23 Principles and Good Practice of Humanitarian Donorship)"6)에서도 인도, 공평, 중립, 독립의 4 개 원칙이 공여국의 인도적 활동의 원칙으로 채택되었다.

가장 최근에는 2014년 12 월 "인도적 지원의 품질과 책무성에 관한 핵심기준(The Core Humanitarian Standard on Quality and Accountability, 이하 CHS)”에서 이 4 대 원칙이 포함되었다. CHS는 인도적 지원을 제공하는 단체와 개인이 지원의 질과 효과성을 제고할 것을 약속하는 9 개의 기준을 제시하는데, 이는 이전에 수립된 지원의 기술적 지침들인 HAP Standard(2010), People In Aid's Code of Good Practice(2003) 스피어(Sphere Project, 2011)를 통합하고 보다 쉽게 적용하려는 의 도에서 만들어 졌다.7) 인도적 원칙은 $\mathrm{CHS}$ 핵심기준의 각 분야에 스며들어 있다 (CHS 2014:8).

제I장

제I장 포함한 공여국 정부와 각종 $\mathrm{UN}$ 기구, 그리고 국제적 $\mathrm{NGO}$ 에서 공식 정책문서를 통 해 인도, 공평, 중립, 독립의 4 대 원칙을 공식적으로 채택하고 있으며 지원활동의 윤 리적, 철학적 근간으로 삼고 있다.

\section{III. 인도적 원칙 분석}

뻭테(Pictet)는 국제적십자사운동의 기본원칙 7가지를 실체원칙(substantive principles), 파생원칙(derived principles), 조직원칙(organic character)의 3가지로 분류하였다. 실체원칙으로는 인도와 공평이 있다. 이 원칙들은 어떠한 경우에도 지켜 져야 하고, 조직에 영감을 주고 조직의 활동을 결정하는, 주관적 영역이 아닌 객관적 영역에 속하는 핵심 원칙(essential principle)이다(Pictet 1979). 이 중 인도의 원칙 은 다른 원칙들이 유래되는 적십자사의 핵심 동기의 표현이라는 특별한 위치를 차지

\footnotetext{
6) Good Humanitarian Donorship Website, http://www.goodhumanitariandonorship.org /gns/principles-good-practice-ghd/overview.aspx(검색일: 2014. 4. 10).

7) Core Humanitarian Standard www.corehumanitarianstandard.org(검색일: 2015.1.16).
} 
한다(Pictet 1979). 또 다른 실체원칙으로는 공평의 원칙에 속하는 무차별성 (non-discrimiation)과 비례성(proportionality)가 있다. 파생원칙(derived principles) 에는 중립과 독립이 있으며 이는 핵심원칙이 실행과 적용을 가능케 하는 일종의 도구 적 원칙들이다(Pictet 1979). 적십자운동의 나머지 원칙들은 조직의 성격과 관련된 원 칙(organic character)들이다(Pictet 1979). 다음에서는 각 원칙과 그 속성에 대해 보 다 면밀한 분석을 시도할 것이다.

\section{1. 인도의 원칙}

인도의 원칙은 인간의 고통은 어디에서 발견되든지 돌봄을 받아야 하며, 특히 가 장 취약 계층에게 중점이 두어져야 한다는 원칙이며, 또한 고통을 받는 사람의 존엄 성과 권리가 존중되고 보호되어야 하는 원칙이다(UN 1991; 대한적십자사 2012:8). 대한적십자사는 인도의 원칙과 관련하여 인간 존엄성에 대한 존중을 강조하고 있으 며 고난을 세계 어디서든지 보편적으로 존재하는 것으로 보고, 방치되어선 안 되며 반드시 대처하여야 한다고 부연한다(대한적십자사 2012:7).

인도라는 개념은 “인류애”의 측면에서 조망할 수도 있다. 워커와 맥스웰(Waker and Maxwell)은 인도의 개념은 인류는 한 가족이라는 인류애(humanity)에서 비롯 된 것이며 도움이 필요한 사람에게 지원을 제공하는 것은 우리의 인류애(humanity) 에 내재되어 있는 속성이라고도 설명한다(Walker and Maxwell 2009:2). 즉, 고통 에 처한 사람이 우리와 같은 인간이라는 이유만으로 도와주는 것이 인도의 가장 기 본적인 철학이며, 이는 그가 어느 국적의 사람이건, 어떠한 정치적 성향을 띄건 상관 없이 돕는다는 의미가 내포되어 있다. 이것은 비록 인류가 국경과 인종 등으로 인해 구분되어 있지만, 결국에는 한 가족이라는 형제애(brotherhood, fraternity)의 관점 으로서도 설명될 수 있다. 따라서 인도에는 “국경을 넘어," “먼 곳의 낯선” 사람들을 돕는다는 의미도 강하게 내포하고 있다(Campbell 1998; Barnett 2009). ${ }^{8)}$ 또한 인도 에는 조건없는, 대가없는 도움을 준다는 의미도 내재되어 있다.

8) 대표적 국제 인도적 단체인 “국경없는 의사회”는 그 이름에서부터 이러한 인도의 개념 을 잘 드러내고 있다고 할 수 있다. 
인도의 개념은 종종 성서에 등장하는 선한 사마리아인의 비유에 빗대어 설명되기 도 한다. 자신과는 아무런 연고도 없는 강도만난(유대인으로 추정되는) 여행객을 당 시 유대인과는 증오의 관계에 있던 사마리아인이 도와 준 상황은 적군과 아군 상관 없이 고통에 처한 자는 누구든지 도와준다는 적십자 정신과도 맞닿아 있다. 즉 고통 에 처한 이방인을 어떠한 대가도 바라지 않고 인간이라는 이유만으로 도와주었기 때 문이다. 또한 인도의 원칙은 "다른 사람이 나에게 해 주길 바라는 방식으로 남을 대 하라”라는 황금률로도 대변될 수 있다(Pictet 1979). 이러한 전통은 불교, 이슬람교 등 기타 다른 종교에서도 발견되지만 워텔(Wortel)은 삑테(Pictet)의 접십자사 철학 은 기독교 전통에 의거한 것이라고 설명한다(Wortel 2009:786).

국제적십자사운동의 기본원칙에 대한 주석을 저술한 삑테(Pictet) 박사는 인도의 원칙은 다른 세 개의 원칙들의 원천이 되는 보편적 원리를 언급하고 있다고 설명한 다. 인도의 원칙은 행동 지침적인 성격의 나머지 세 원칙들과는 달리 포괄적인 성격 을 띠고 있으며 이하 다른 원칙들이 흘러나오는(flow from) 근원이라고 할 수 있다 (Pictet 1979). 오랜 기간 옥스팜(Oxfam)의 인도적 지원 활동가로 일했던 토니 복스 (Tony Vaux)도 인도적 원칙이란 인도주의의 근본적인 윤리적 가치를 대표하며, 이 원칙은 다른 기타 원칙들보다 우위를 차지한다고 설명한다(Vaux 2001:5). 이 원칙은 지원을 수행하는 방식이라기보다는 지원을 제공하는 근본적 동기에 관한 것이다 (Mackintosh 2000:7).

한 가지 주목할 만한 사안은 1994년에 수립된 적십자운동과 $\mathrm{NGO}$ 의 행동강령에서 는 “인도의 요구(humanitarian imperative)"라는 표현 아래, 인도적 지원을 제공할 권리와 받을 권리는 가장 근본적인 인도적 원칙이라고 강조하며 인도적 지원을 권리 (right)의 영역으로 간주하고 있다는 점이다. 이는 인도적 지원의 제공과 수원이 보 다 능동적으로 추구되어야 할 권리로 해석하는 것으로써 이후의 스피어(Sphere) 등 의 지침서에 볼 수 있는 인도적 지원의 인권적 접근의 시작점이라고 볼 수 있다.

인도의 원칙은 단지 육체적인 안녕(well being)만을 의미하지 않는다(Vaux 2001:8). 구호는 배를 채우기 위한 칼로리나 갈증을 해결하기 위한 물을 제공하는 것 뿐 아니라, 한 인간의 마음, 상실감, 신분하락 등의 심리적, 정서적 필요까지 고 
려해야하는 전인적인 것이다(Vaux 2001:8). 이러한 측면에서 인도적 지원은 매우 요 구하는 바가 큰(demanding) 작업이며 아무리 부어도 채울 수 없는 밑 빠진 독에 물 붓기 같은 작업과 같다. 이러한 이유로 많은 인도적 지원 종사자들은 불안과 죄책감 을 가지게 된다고 고백하고 있다(Vaux 2001:8). 이는 오랜 기간 현장경험가로 활동 한 복스(Vaux)의 지난한 고뇌가 반영된 성찰이라고 할 수 있다.

\section{2. 공평의 원칙}

공평의 원칙은 인종, 성별, 국적, 종교, 계층, 정치적 성향에 관계없이 가장 필요 한 사람에게 차별 없는 지원이 이루어 져야 할 것을 의미한다(Pictet 1979; UN 1991). 워커와 맥스웰(Walker and Maxwell)은 한정적인 자원과 대립되는 이해관계 가 난무하는 현 위기상황에서 인도의 원칙을 구현하기 위해서는 “요령(caveat)”이 필 요하며, 공평의 원칙이 이 요령을 제공한다고 보았다(Walker and Maxwell 2009:2). 인도적 지원은 필요의 강도(severity)와 시급성(urgency)이라는 두 축에 의해 작동되 고 있다고 해석하였다(Pictet 1979; Walker and Maxwell 2009:2). 다음에서는 공평 의 원칙을 삑테(Pictet)가 분류한 방법인 무차별성(non-discrimination), 비례성 (proportionality), 공평성(impartiality)의 세 속성으로 세분화 하여 분석할 것이다 (Pictet 1979; 대한적십자사 2012:8).9)

\section{1) 무차별성(non-discrimination)}

무차별성은 도움을 받는 사람에 대해 어떠한 차별도 두지 않는 것으로 간단히 정의 할 수 있는 속성이다(대한적십자사 2012:8). 이에 대해 적십자운동은 “종교적 믿음, 피부색, 정치적 신념, 출신, 경제”적 지위에 상관없이 도움이 필요한 모든 사람에게 도움을 제공하는 인도주의의 핵심가치라고 설명한다(대한적십자사 2012:8). 제네바 협약의 공통조항(Common article) 제 3 항에서도 “모든 경우에 있어서 인종, 색, 종교 또는 신앙, 성별, 문벌이나 빈부 또는 기타의 유사한 기준에 근거한 불리한 차별 없 이 인도적으로 대우하여야 한다”라고 분명히 명시하고 있다(대한적십자사 2010).

9) 무차별(non-discrimination)과 비례성(proportionality), 공평성(impartiality)의 한국어 번 역은 대한적십자사의 번역을 따랐다(대한적십자사 2012). 
삑테(Pictet)는 무차별성을 설명하며 다음 예화를 제시하였다(Pictet 1979). 세계 제 2차 대전이 끝날 무렵, 전쟁에 참여했던 한 소대가 본국으로 귀국하여 어느 마을 을 지나게 되었다. 소대를 이끄는 장교가 마을 병원의 여성 책임자에게 치료받아야 할 부상병이 있다고 알린다. 그러나 그 여성 책임자는 병원이 적군들에 의해 다 찼 다며 받아 주지 않는다. 그 장교는 적군을 나가게 하고 아군의 부상병을 치료해 달 라고 하지만, 여성은 거절한다. 잠시 당황한 장교는 부상당한 적군은 더 이상 적이 아니라는 점을 깨닫고 치료를 종용하지 않고 다른 마을의 병원을 찾아 떠난다. 이 예화는 국적과 관련하여 무차별성을 적용한 사례라고 할 수 있다. 이것은 루이스 파 스퇴르(Louis Pasteur)의 "오늘날 우리는 고통에 처한 사람에게 어느 나라에서 왔는 지, 종교는 무엇인지를 따지지 않는다. 우리는 단지 그가 고통을 느끼고 있고, 그는 우리와 동등하고(one of our own) 우리는 그에게 구호를 제공할 것이라고 말할 뿐 이다”라는 설명으로 요약할 수 있다(Pictet 1979).

제 I장

제I장 간사이의 권리의 평등(equality of rights among men)이라고 지칭하며 인간의 필요 는 불평등할 수 있지만, 인간의 권리는 평등하다고 해석한다. 즉, 고통 받는 모든 인 간의 고통의 정도와 결핍의 정도는 다르지만, 이들이 지원을 받을 수 있는 권리는 평등하게 주어진다는 의미이다. 이는 웰러(Weller)의 분석에서도 잘 나타나는데, 그 는 무차별성이란 지원의 기준이 지원을 필요로 하는 모든 당사자에게 동등하게 적용 되어야 한다는 것이지, 모두가 같은 양의 지원을 받는 다는 것을 의미하지는 않는다 고 역설하였다(Weller 1997).

\section{2) 비례성(proportionality)}

비례성은 가장 위급한 재난부터 우선적으로 도와야 하며 가장 많은 도움을 필요로 하는 사람에게 지원이 우선적으로 수행되어야 한다는 개념이다(대한적십자사 2012:8). 양적으로는 가장 많은 도움이 필요한 사람에게, 시간적으로는 생명유지를 위한 시간이 가장 부족한 사람에게 지원이 이루어 져야 함을 뜻하는데, 여기에는 자 원이 불평등하게 배분된다는 의미를 포함하고 있다. 앞서 언급한 무차별성의 경우 
지원 대상자는 평등하게 간주하지만, 비례성의 경우 지원의 배분은 불평등한 행위임 을 나타낸다. 즉, 무차별의 원칙이 평등의 원칙이라면 비례의 원칙은 공정의 원칙 (principle of equity)이다(Pictet 1979; Vaux 2001:5). 사람마다 필요의 정도와 분 야가 다르기 때문에 인도적 지원 수혜를 위한 평등한 기회를 제공하는 것만으로 평 등한 결과를 초래하지 않는다. 따라서 사람마다 필요에 따른 분배의 조정이 필요하 다. 이러한 면에서 공정성(equity)은 평등(equality)를 달성하는데 핵심적인 요소라고 할 수 있다. ${ }^{10)}$ 불평등한 자원 배분을 통하여 공정성(equity)이 실현되기 때문이다.

앞서 언급했던 아군 부상병수용을 거부했던 간호사의 예화에 비례성의 원칙을 적 용할 수 있다. 그 상황에서 아군과 적군의 부상병 중 그 정도가 가장 심각한 부상병 (당장 입원이나 수술이 필요한 사람)에게 치료의 우선순위를 부여하고, 경미한 부상 을 당하여 이동에 문제가 없는 군인은 -적군이든 아군이든- 다른 병원으로 이송하 는 것이 비례성의 원칙을 엄격하게 적용한 예가 될 것이다(Pictet 1979).

비례성을 고찰함에 있어서 뻭테(Pictet)는 또 다른 예화를 소개한다. 당신이 집에 서 외출을 했는데, 집 문 앞에 두 명의 노숙자가 있다. 만약 시간이 없다면 두 노숙 자에게 동일한 금액의 돈을 줄 것이다. 그러나 그들을 찬찬히 볼 시간이 있다고 치 자. 한 사람은 나이가 많은 노인이며 당신은 이 노인에게 더 많은 액수를 줘야겠다 고 생각한다. 그런데 옆의 노숙자는 비록 젊지만 한쪽 팔이 없다. 이 젊은 사람이 더 많은 지원을 필요로 하지 않겠는가? 만약 그들의 이야기를 들을 시간이 더 있었다고 치자. 노인은 난민이고 일가친척 의지할 데 없이 홀로 남겨졌다는 것을 알게 된다. 이번엔 젊은이는 부양해야할 가족이 있음을 알게 된다. 뻭테(Pictet)는 이런 식으로 지원하는 입장에서는 어느 한 쪽을 편애하는 것에 대한 합리화를 계속 늘려갈 수 있 다고 지적하며, 고통을 경감시키는 데에 있어서 대상자의 필요를 구분하는 것은 거 대한 노력과, 시간과 사랑이 필요한 어려운 작업임을 지적하고 있다(Pictet 1979).

10) 양성평등(gender equality)와 성형평성(gender equity)의 개념을 인도적 지원에 적용하 여 분석한 것이다. 공정성(equity)은 형평성으로 번역되기도 한다. 출처: "Difference between Gender Equality and Gender Equity" http://vcampus.uom.ac.mu/soci1101/432_difference_between_gender_equality_and _gender_equity.html(검색일: 2015.1.19). 
이 예화는 어쩌면 매우 상식적인 개념인 비례성의 실현을 위해 중요한 전제가 있 음을 보여 준다. 가장 도움이 필요한 사람이 누구인지에 대한 정확한 정보가 있어야 한다는 점이다. 이를 위해서는 외부의 영향을 받지 않는 독립된 조사체계를 통해서 객관적으로 누가 가장 도움을 필요로 하는지 평가할 수 있어야 한다(Pictet 1979; 대 한적십자사 2012:8). 적십자운동과 NGO 행동강령(1994)에서는 "가능한 어디서든지 재난 피해자의 필요와 그 필요를 충족시키기 위해 현장에 있는 현지 역량에 대한 온 전한 평가에 의거해 지원을 제공한다”고 구체적으로 명시하고 있다(ICRC 1994). 이 는 인도적 단체의 독립성이 보장 되어야만 공평의 원칙이 실현될 수 있다는 점을 시 사하고 있으며, 추후 설명할 독립의 원칙과도 연결되는 부분이다.

제I장

제I장 가능하였다. 2008년 9월 스리랑카의 경우, IDP가 몰려있는 북부지역에서 국제기구들 이 철수한 이후에는 이 지역에의 접근이 봉쇄되었다(Collinson, Buchanan-Smith and Elhawary 2009:6). 당시 인도적 지원을 수행했던 한 관계자는 "수혜자가 어떻 게 선정되고 우선순위가 결정되는지 알 길이 없다”고까지 증언했던 것으로 전해진다 (Collinson, Buchanan-Smith and Elhawary 2009:6).

이와 같이 비례성이 완벽히 적용된 상황은 현실에서는 매우 드물다. 원칙이 추구 하는 높은 이상과는 달리, 국제 적십자사를 제외한 현재 많은 공여국들과 국제 NGO 들은 분쟁의 한 편에만 인도적 지원을 제공하고 있다. 매킨토시(Mackintosh 2000) 는 이러한 상황에 대해 "(비례성의 적용을 위해서는) 가장 큰 필요가 있는 곳에 대응 하도록 지원 프로그램이 설계되어야 하지만, 실질적인 운영상의 이유로 분쟁의 한 편만 지원을 한다고 해서 인도적이라고 불릴 귄리를 박탈당하지는 않는다”라고 변호 한다(Mackintosh 2000:8). 


\section{3) 공평성(impartiality)}

공평성에 대하여 국제적십자운동에서는 “적십자운동에 참여하는 모든 구성원은 반 드시 개인적 선호나 편견을 인도주의 활동에 개입시켜서는 안된다”라고 설명하고 있 다(대한적십자사 2012:8). 이는 모든 결정을 내림에 있어서 반드시 객관적인 근거를 바탕으로 하며 개인적인 감정이나 선입견을 배제하는 것을 뜻한다(대한적십자사 2012:8; Mackintosh 2000:8). 무차별성이 객관적으로 구분된 기준에 의거한 차별을 두지 않는 것을 의미한다면, 공평성은 개인적 주관적 취향에 의한 차별을 하지 않는 것이다(Pictet 1979). 예를 들면 무차별성이 인종, 종교, 정치적 성향 등 보편적으로 인정하는 어떠한 “다름"에 대해 차별을 가하는 것이라면, 공평성(impartial)은 같은 집단 내에서라도, 개인적이고 주관적인 감정의 선호도에 의해 차별이 가해지는 것을 말한다(Pictet 1979). 따라서 공평성은 보다 주관적 영역에 속한다. 복스(Vaux)는 지 원 대상을 구분하지 않는다는 면에서 공평은 인도(humanity)의 핵심 속성이라고 강 조하였다(Vaux 2001:5). 나아가 "필요에 처한 사람(person in need)에 대한 포괄적 인 이해에 다다르기 위해서는 개인적 편견과 선입견을 버려야 한다”고 지적하고 있 다. 이것은 지속적인 자아성찰, 효과적인 의사전달, 그리고 쉬지 않는 분석 작업을 요하는 매우 어려운 요구이다(Vaux 2001:5).

공평의 원칙을 분석함에 있어서 한 가지 염두에 두어야 할 사항은 유엔난민기구 (UNHCR)의 정관 제 7 조 $\mathrm{d}$ 항에 의하면 $\mathrm{UNHCR}$ 은 국제적 범죄의 범법자에게의 지원 을 금지하고 있다는 점이다(UNHCR 1986). ${ }^{11)}$ 무차별성 혹은 공평성 (proportionality)에 의하면 인도적 지원이 필요한 사람은 필요 그 자체로만 지원의 양과 질이 결정되어야 한다. 하지만, $\mathrm{UNHCR}$ 은 국제범죄자의 경우에 난민 혹은 난 민인정 대기자가 마땅히 받아야 할 인도적 지원을 원천 봉쇄하고 있다. 매킨토시 (Mackintosh)는 이러한 인도적 원칙과 UNHCR의 입장 사이에서의 혼란이 1994년 르완다학살 이후 Great Lakes 지역에서 난민캠프 운영에서 드러난 문제에 기여했을 수 있다고 지적한다(Mackintosh 2000).12)

11) UNHCR 정관(1950) 7조 d항. http://www.unhcr.org/3b66c39e1.pdf.

12) 1994년 르완다 대학살 직후 이를 주도한 후투족들이 주변국의 난민캠프로 피신하였다. 후투족들은 이 곳에서 난민의 혜택을 누리며 재무장하였는데, 이로 인해 인도적 단체들 은 범죄자들을 지원한다는 비난을 면치 못하였고 많은 갈등 끝에 결국 철수하였다. 


\section{3. 중립의 원칙}

국제적십자운동(RCRC Movement)의 정관의 서문에 의하면 중립이란 “지속적으로 모든 사람의 신뢰를 받기 위해, 적대행위가 있을 때 어느 편에도 가담하지 않고 어 떤 경우에도 정치적, 인종적, 종교적 또는 이념적 성격을 띤 논쟁에 개입하지 않는 것”이다. ${ }^{13)}$ 스위나르스키(Swinarski)는 중립을 “분쟁 시 한 쪽 편의 이익을 추구하는 혹은 한 쪽 편을 위험에 빠트리는 어떠한 행동으로부터 회피하는 의무(duty to abstain)”라고도 설명하였다(Swinarski 1984:823, Plattner 1996에서 재인용). 국제 적십자사와 $\mathrm{NGO}$ 행동강령에서는 중립의 원칙을 “인도적 지원은 특정 정치 종교적 입장을 지지하는 데에 사용되지 않아야 하며 특정 정책 혹은 종교적 신념을 포함 (embrace)하거나 수용(accept)하는 조건으로 지원, 약속, 전달, 배분하지 않는 것”이 라고 설명하고 있다(ICRC 1994). 인도적 지원에 있어서 중립은 대립하는 양측을 전 제로 하며 통상 자연재해보다는 분쟁 상황을 그 배경으로 한다.

현재 인도적 지원활동의 원칙으로 채택되고 있는 중립의 원칙은 국가 간 무력충돌 의 발생시, 이에 참가하지 않는 국가의 상태를 의미하는 개념인 “중립국(neutral state)"에서 발달하였다(Plattner 1996; 김성원 2012). 중립국에서 출발된 법적 개념 인 중립은 이후 국제적십자위원회의 단체의 운영철학으로 옮겨가게 된다. 앞서 살펴 보았듯이 1965 년 제 20 차 국제적십자회의에서는 국제적십자운동의 7 대 원칙(Seven Fundamental Principles of International Red Cross and Red Crescent Movement)중의 하나로 중립을 채택하였다. ${ }^{14)}$ 1985년 채택된 국제 적십자 운동(The International Red Cross and Red Crescent Movement)의 정관(statute)에서도 국 제 적십자사를 “중립적 기구” 혹은 “중립적이고 독립적인 기구”로 명시하고 있다. 이 러한 과정을 거쳐 중립국에게 부여되는 권리와 의무를 포함하는 지위로 이해되었던 “중립”이 비 국가 조직에 적용되게 되었다. 이와 관련 Plattner(1996)는 “국제적십자

13) ICRC. 1986. Statutes of the International Red Cross and Red Crescent Movement. http://www.icrc.org/eng/assets/files/other/statutes-en-a5.pdf(검색일: 2015.1.15) 번역은 대한적십자사에서 발간한 “국제적십자운동 기본원칙(2012)”에서 참조하였음).

14) 국제적십자운동은 국제적십자위원회(ICRC), 국제적십자연맹(IFRC), 그리고 각국의 적십 자사(National Red Cross and Red Crescent Societies)의 세 기구로 이루어져 있다. 적십자운동의 7 대 원칙으로는 인도(humanity), 공평(impartiality), 중립(neutrality), 독립 (independence), 봉사(voluntary service), 단일(unity), 보편(universality)이 있다. 
위원회(ICRC)를 공평하고도 중립적인 기관으로 명시하는 것은 국가들이 국제적십자 위원회에 국제법인격(international legal personality)을 부여한 것이며, 중립국의 지위의 구성요소를 부여한 것”으로 해석한다(Plattner 1996). 중립의 원칙은 이후 1992년 UN, 공여국 정부, 국제 $\mathrm{NGO들의} \mathrm{활동} \mathrm{원칙으로} \mathrm{공식적으로} \mathrm{채택되는} \mathrm{과정}$ 을 통하여 인도적 지원을 수행하는 비정부기구들의 활동 원칙으로 자리 매김하게 되 었다.

중립은 그 자체가 목적이 아니며, 인도적 지원을 가능하게 하는 도구적 역할을 한 다(UN OCHA 2004:14-15).15) 인도적 지원 단체가 분쟁에 대해 철저하게 중립을 유 지할 때 분쟁 당사자들은 이들이 분쟁의 어느 편도 들지 않을 것이라는 신뢰를 할 수 있게 된다(Harroff-Tavel 2003:3; Amar 1998; Plattner 1996). 이렇게 확보된 신뢰는 다음 사항을 위해 필수적이다. 첫째, 중립으로 확보된 신뢰는 인도적 지원 단 체가 도움이 필요한 지역에 접근(access) 할 수 있게 해 준다. 스리랑카에서 국제적 십자위원회는 중립으로 확보한 신뢰를 바탕으로 정부군점령지역과 타밀반군점령 지 역 간에 민간인 및 물자 이동을 주관하였고, 또한 전사자들을 이송하여 치료를 받게 하였다. 둘째, 중립을 유지하는 것은 가해자의 인권유린을 중지시키기 위한 설득 (persuasion)을 가능케 한다. 아마르(Amar)는 "국제적십자위원회의 가장 큰 목표인 분쟁의 피해자들을 돕는 여러 방법 중 하나는 분쟁 당국을 '설득'하는 것인데, 피해 자들을 대신해서 인권 침해 혹은 인도법을 위반을 하는 정부를 설득하려면 이들을 공개적으로 비판하고서는 불가능하다”고 주장한다(Amar 1998). 셋째, 중립으로 얻게 된 신뢰는 인도적 구호요원의 안전을 보장해준다. 2013년 현재 분쟁상황에서 인도적 구호요원들의 납치, 폭행, 살해 등을 포함한 피해 건수는 2000년 91명에서 2012년 274명으로 급격히 증가하고 있다(Harmer, Stoddard and Toth 2013:1). 그러나 중 립을 단체의 운영철학으로 유지하는 국제적십자위원회의 경우 이 기간 동안 피해 수 치는 한자리 수에 머물 정도로 현저하게 낮다(Harmer et al. 2013:1).

15) 이러한 도구성 때문에 중립은 “실용적 원칙("pragmatic' principle)”으로도 불린다. Humanitarian advocacy in Darfur: the challenge of neutrality. October 2007. HPG Policy Brief 28. p. 1

http://www.odi.org/sites/odi.org.uk/files/odi-assets/publications-opinion-files/476 .pdf(검색일: 2015.1.15). 
중립 원칙은 냉전종식 이후 국가 내 분쟁으로 전쟁의 양상이 변화하는 상황에서 그 적절성에 대한 논란이 증가하고 있다(Plattner 1996; Vaux 2001:5; Walker and Maxwell 2009:3; McGoldrick 2011) 중립의 원칙을 폐기해야 한다고 주장하는 입장 은 해당 정부가 자국민을 극도의 인권 유린과 박해의 현장으로 내모는 상황(인종청 소, 제노사이드, 전쟁의 수단으로서 기아 등)에서 분쟁 당사자의 어느 편도 들지 않 는 중립의 원칙을 고수하는 것은 비윤리적이며 심지어는 죄악이라고 까지 비난한다 (Udombana 2005). 1967-70년 나이지리아 내전 당시, 나이지리아 정부군과 비아프 라 반군 사이에서 중립을 고수했던 국제적십자사는 정부군의 압력에 굴복하여 비아 프라 지역의 지원을 중단하였다. 이는 비아프라 주민의 대대적 희생으로 이어졌다. 특히 인권적인 측면에서 피해자와의 연대를 강조하는 지원 단체들은 국제적십자사의 침묵은 지원하지 않는 것에 대한 변명에 불과하다며 강하게 비난하였다. 이러한 구 도는 냉전 종식 후 전쟁의 양상이 국제전에서 내전으로 변화하면서 심화되었다. 현 재까지도 국제적십자사는 중립을 절대적 가치로 고수하고 있으나 다수의 $\mathrm{NGO}$ 의 경 우 중립을 보편적이거나 절대적인 가치가 아닌 상대적인 가치로 간주하고 있다 (Weller 1997; Walker 2004). 국경없는의사회(MSF)의 경우 명목상으로는 중립을 유 지하고 있으나 “의견표명활동(speaking out)”을 통해 인권유린을 자행하는 해당 정부 를 공개적으로 비난하고 피해자들을 대변하는 것을 운영 철학으로 채택하고 있다. 옥스팜(Oxfam), 세이브더칠드런(Save the Children)과 같은 단체들도 명목상의 중 립원칙 고수에도 불구하고 피해자와의 연대를 강조하고 있다.

가장 최근에는 2014년 인도적 지원에 관한 핵심기준(Core Humanitarian Standard, CHS) 수립을 위한 1,2 차 초안을 거치는 과정에서 중립원칙이 아예 삭 제되었다가 최종 문서에서 다시 복원되었다. 채택된 최종문서에서는 인도적 원칙이 다른 원칙들 중 가장 마지막에 위치해 있으며, "인도적 지원 기관은 공평한 지원과 분쟁에 있어서 편들지 않는 것을 약속함에도 불구하고 중립을 지킨다는 것이 책무성 과 정의에 관련된 사안들에 대해서 옹호하는 것을 배제하지는 않는다”라고 밝히고 있 다(CHS 2014:8). 즉, 명백한 정의를 실현하기 위해서 한 편을 옹호해야 하는 경우에 는 중립을 포기하겠다는 입장이다. 이는 국경없는의사회(MSF)가 중립을 표방하고 있 지만, 피해자와의 연대를 강조하며 증언(witness)의 정책을 택하고 있는 것과 비슷한 맥락이다. 2016년 개최될 인도주의 정상회담(World Humantiarian Summit)을 위한 
예비 프로세스에서도 중립은 논의의 핵심이 되고 있으며 중립의 문제로 온라인 자문 이 개최되는 등 활발한 논의가 진행되고 있다. ${ }^{16)}$

\section{4. 독립의 원칙}

마지막으로 독립의 원칙은 “정치적, 경제적, 군사적 혹은 인도적 지원이 실행되는 곳에서 어떤 행위자가 실현하고자 하는 기타 목적으로부터의 인도적 목적의 자율성” 이라고 정의할 수 있다(UN 1991). 국제적십자사와 NGO 행동강령에서는 “정부 정책 의 도구로 사용되지 않는 것”이라고 보다 간략하게 표현하고 있으며 이를 보다 구체 적으로 설명하면 다음과 같다(ICRC 1994).

“우리는(국제적십자사와 NGO) 정부의 외교적 도구로 쓰이지 않기 위해 노력해야 한다. 비정부 인도적 기관들은(non-governmental humantiarian agencies)는 정부 로부터 독립적으로 활동한다. 따라서 우리의 정책과 실행전략을 스스로 수립한다. 또 한 우리의 독립적 정책과 일치하지 않는 어떠한 정부의 정책도 실행하지 않는다. 개 인이나 단체가 의도적이든 의도치 않던 특정 정부나 단체를 위해 인도적 목적 이외 의 정치, 군사, 경제적으로 예민한 정보 수집하는 데 사용되는 것을 결코 허락하지 않는다. 지원물자는 필요를 공급하는 데에만 사용할 것이며 공여국 정부의 잉여 생 산품의 처분을 위하거나, 특정 공여국의 정치적 목적을 충족시키기 위해 사용하지 않을 것이다. 우리는 개인의 자발적 노동력과 재정적 기부를 중요하게 생각하며 그 러한 자원봉사의 동기에 의한 활동의 독립성을 인정한다. 우리의 독립성을 보호하기 위해 우리는 한 단체로부터의 재정적 원천에 의존하는 것을 기피한다(ICRC 1994).

독립 원칙 준수에의 어려움은 국제적십자사 설립 초기부터 존재했던 것으로 보인 다. 적십자사는 독립적인 기구이기도 하지만, 공공단체로서의 속성도 지니고 있기 때 문이다. 특히 각 국 적십자사의 경우 자국 정부의 보조역할을 하고 자국의 법을 따 라야 하는 이중적인 성격을 띠고 있다. 때문에 설립 초기 멤버인 귀스타브 므와니에 (Gustave Moynier)도 1864년 8월에 이미 “상호 배타적인 두 측면, 즉 사설 자선단

16) 2015년 1월 8일 "21세기 인도적 에 있어서의 중립(Neutrality in 21st century humanitarian operations)"이라는 주제로 온라인 토론이 개최되었다. 
체로서의 자유와 군사 규칙의 준수의 두 가지를 조화시키는 데 있어서의 어려움”을 지적하였다(Pictet 1979). 뻭테(Pictet)는 그럼에도 불구하고 적십자사의 원칙을 유지 하기 위해서 자율성(autonomy)을 지키는 것이 필수적임을 설파하였다(Pictet 1979).

9/11 이후, 테러와의 전쟁이 시작되면서 인도적 지원은 도구화 되었고 독립적 활 동에 있어서 제약을 경험하게 된다. 미 국무부 아프가니스탄 특별대사 리처드 홀브 룩(Richard Holbrooke)은 테러와의 전쟁 수행을 위한 현지 정보 수집에 있어서 $\mathrm{NGO}$ 의 중요성을 강조하였다. 아프간 작전 초기에 당시 미국 국무장관 콜린 파월 (Colin Powell)이 국제 $\mathrm{NGO}$ 를 지칭하며 “미국 전투력의 일원”이며 “전력승수(force multipliers)"라고 언급한 예화는 유명하다. NATO 사무총장을 지낸 안데르스 포그 라스무센(Anders Fogh Rasmussen)은 2010년 재직 당시 한 연설에서 위기관리에 있어서의 민군협력의 중요성을 강조하면서, 아프간에서 민간단체와 군대와의 협력은 이후 NATO와 NGO의 협력의 “원형(prototype)“이라고 강조하였다(Anders Fogh Rasmussen 2010, Ferreiro 2012에서 재인용). 이는 인도적 활동이 더 이상 순수한 인도적 목적에 의거하여 수행되는 것이 아닌, 다양한 정치적, 안보적, 개발적, 경제 적, 또는 그 이외의 비인도적 목적에 종속되는 것을 의미한다.

이러한 현상은 특히 인도적 개입이 확대된 1990년대 후반부터 9/11 이후 미국의 테러와의 전쟁 선포이후 본격적으로 심화되었다. 인도적 지원은 반군소탕작전 (counter-insurgency operation)의 효과적 수행을 위해 종종 이용되어 왔다. ${ }^{17)}$ 비 근한 예로, 아프간 지방재건팀(Provincial Reconstruction Team, PRT)이 탈레반과 알카에다 관련 정보를 제공받는 것을 조건으로 지역주민들에게 인도적 지원을 제공 했다는 것은 공공연하게 알려진 사실이다(Terry 2011:175). 또한 대테러 전쟁이라는 거시적인 전략 목표 아래 많은 국제 $\mathrm{NGO들이} \mathrm{미국} \mathrm{정부의} \mathrm{용역업체로서} \mathrm{고용되어}$ 인도적 지원을 수행하게 되었다. 이와 같이 분쟁 당사자 어느 한 편의 이익을 위해 인도적 지원을 수행하는 상황에서 인도적 지원 단체들이 중립과 독립적 위치를 고수 한다는 것은 불가능하다(Stoddard 2003:5-7).18) 현재 공여국 정부의 개입이외에도

17) 인도적 지원은 반군소탕작전(counter-insurgency operation)의 일환으로 사용되고 있 다. 즉, 인도적 물자 및 서비스 제공을 통해 주민의 마음을 얻고(winning hearts and minds) 반군의 정보를 얻어내는 것을 목적으로 하는 계획이다. Gordon(2011) 참조.

18) 2001년 이후 미국의 대테러전의 일환으로 이라크에서도 유사한 상황이 전개되었다. 
월마트(Walmart)를 비롯한 사기업들이 인도적 지원에 뛰어들고 있다. 이러한 상황에 서 인도적 지원은 공여국의 정치적 전략과 기업의 이익달성이라는 목적에서 자유롭 지 못하게 된다(Hopgood 2008).

\section{5. 원칙간의 상관성}

개별 원칙의 검토를 통해 알 수 있는 것은 이 원칙들이 상호배타적이지 않으며, 원칙 간에 공통적인 속성들이 발견된다는 점이다. 또한 한 원칙은 다른 원칙의 실현 을 가능케 하는 전제가 되는 등 서로 밀접하게 연관되어 있다. 인도의 원칙은 지원 의 근본적인 동기로서 작용하며 나머지 세 원칙을 아우르는 성격을 지닌다. 복스 (Vaux)는 인도적 지원에 있어서 원칙, 행동강령, 세부기준 등이 존재하지만 이는 모 두 인도라는 개념 하나로 대체될 수 있다고 그 중요성에 대해 강조하였다(Vaux 2001:5). 인도는 또한 공평의 원칙과도 여러 속성을 공유한다. 이러한 이유로 삑테 (Pictet)는 인도와 공평을 핵심원칙(essential principle)으로 구분하였다.

차별 없는 공평한 지원을 위해서 단체들은 중립적인 입장을 고수해야 하고 독립적 으로 의사결정을 할 수 있어야 한다. 즉, 중립과 독립은 공평의 원칙을 실현할 수 있 게 해 준다. 또한 독립은 중립을 보장해 준다. 앞서 살펴본 아프가니스탄 예에서도 알 수 있듯, 한 단체가 정치, 경제, 군사적 목적에 종속되어 있는 상황에서는 중립을 지키기가 어렵다. 이러한 의미에서 중립과 독립은 파생원칙(derived principle) 혹은 실행원칙(operation principle)으로써 작용하고 있다(Pictet 1979; Walker and Maxwell 2009:2-3).

Nickolls(2003:7-9) 참조. 


\section{IV. 인도적 원칙에의 도전과 유효성}

\section{1. 인도적 원칙에의 도전}

지원의 동기와 핵심 가치를 대변하는 인도와 공평의 원칙, 지원의 실행을 용이케 해 주는 중립과 독립의 원칙의 이상적인 조합에도 불구하고 인도적 원칙은 그 실행 에 있어서 어려움을 겪고 있다. 가장 큰 원인으로는 무엇보다 인도적 원칙의 이론적 이고 철학적인 성격으로 인해 이 원칙들을 문자 그대로 실전에 적용하기란 쉽지 않 다는 점이다(Pictet 1979).

제 I장

제I장 한계, 3) 피해지역 접근이 확보되지 않은 지역에서 공평적 지원이 불가능한 점; 4) 자금 수혜를 위한 지원 단체 간의 경쟁과 분열이 가져오는 취약성 등이 포함된다. 이와 더불어 미디어의 주목을 받는 위기에만 지원이 집중되는 상황, 신속한 예산지 원을 위협하는 지나치게 관료적 조건들도 가장 필요로 하는 곳에의 공평한 지원을 어렵게 만드는 구조적인 원인으로 작용한다(NRC 2012:39).

나아가 조직차원과 개인 차원에 기인하는 문제도 있다. 노르웨이 난민위원회 (Norwegian Refugee Council)의 사무총장을 지낸 엘리자베스 라무손(Elisabeth Rasmusson)은 인도적 원칙에 대한 미흡한 이해와 조직업무에의 미통합을 문제점으 로 지적하였다(NRC, 2012:39; IASC 2010:16-17). 이런 경우는 인도적 커뮤니티 전 체에 대한 인식과 대우에 부정적인 영향을 줄 수 있다는 점에서 문제를 야기한다. 예를 들면 단체의 운영 지침에 인도적 원칙이 통합되지 않은 경우 혹은 단체의 수장 이 인도적 원칙에 대한 감수성이 결여된 경우, $\mathrm{NGO}$ 가 분쟁의 한 당사자로부터 무장 경호(에스코트)를 제공받는 것에 대해 문제의식을 전혀 느끼지 못하는 경우가 있다. 무장 경호를 통한 지원은 단기적으로는 피해지역으로의 접근을 확보해 주지만, 장기 
적으로는 다른 $\mathrm{NGO}$ 들의 정체성과 안전을 위협하게 된다(NRC, 2012:39). ${ }^{19)}$ 이러한 이유에서 인도적 원칙의 조직차원의 내재화(internalization)가 필요하며 집단적으로 차원에서의 숙지가 필요함을 지적하였다(NRC, 2012:39).

힐호스트와 슈마이만(Hilhorst \& Schmiemann)은 국경없는의사회(M decins Sans Fronti res, MSF)의 현장 구호요원들과의 면담을 통한 연구에서 다음 사항들 을 지적하고 있다. 급박하게 전개되는 위기 상황, 낯선 환경, 하루 12 시간 이상의 근 무, 체력적인 고갈, 안전에의 위협, 빠른 직원 회전율 등의 긴급 상황에서 일하는 구 호 요원들은 매일 주어진 업무를 수행하는 것에만 집중하게 되며, 인도적 원칙에 대 해 깊이 생각할 여유가 없다(Hilhorst \& Schmiemann 2002:495-6). 또한 인도적 지원 활동 중에 맞닥뜨리게 되는 윤리적 딜레마에 대해서도 깊이 있는 성찰이 결여 된다고 언급하였다. 아울러 현장 활동가들은 인도적 원칙에의 적용에 있어서 실제적 인 지침이 없다는 이유로 논란의 소지가 있는 활동에 대해 합리화 하고 타협하는 성 향을 보였다. 현지 사무소장과 조직의 원칙에 관한 논의의 기회가 있긴 하지만, 이는 12 시간이나 격무 후 진행되는 논의는 수박겉핝기 식으로밖에 진행되고 있었음을 발 견하였다(Hilhorst \& Schmiemann 2002).

조직의 철학과 개인의 철학이 상이할 때 겪게 되는 윤리적 딜레마도 있다. 한 간 호사의 경우, 옆 마을에서 비위생적으로 행해지는 여성할례에 대한 소식을 듣고 개 인적으로 그들에게 위생적인 의료 기구를 지원하고 싶었으나, 여성할례에 반대하는 $\mathrm{MSF}$ 공식입장을 따를 수밖에 없었다고 증언하였다(Hilhorst \& Schmiemann 2002:495-6). MSF는 난민이 아닌 근처 지역 주민에게 인도적 지원을 제공하는 것 을 정책적으로 금지하고 있는데, $\mathrm{MSF}$ 의 한 구호팀은 이러한 정책이 중립의 원칙에 반하는 것으로 판단하고 지역주민에게도 지원을 강행하였다(Hilhorst \& Schmiemann 2002:498). 이러한 예는 높은 이상으로서의 인도적 원칙, 보다 현실적 인 조직의 원칙, 그리고 지원을 수행하는 개인의 철학이 일치하지 않을 때 발생할 수 있는 문제점을 잘 보여준다.

19) 그러나 라무손(Ramusson)의 경우는 인도적 원칙의 엄격한 준수를 강조하는 입장이 며, 실질적으로 단체마다 원칙의 적용에 있어서 그 정도에 차이가 있다. 무장경호의 고용에 있어서도 너그러운 단체가 있는가 하면 국제적십자사와 같이 허용하지 않는 경우도 있다. 


\section{2. 인도적 원칙의 유효성}

인도적 원칙의 적용에 있어서의 구조적, 조직적, 개인적 차원의 도전에도 불구하고 많은 단체들이 이 원칙을 포기하지 않는 이유는 무엇일까? 매번 동일하지 않은 인도 적 위기 상황에서 활동의 적합성 여부를 판단할 때, 인도적 원칙이 나침반이자 기준 점(reference point)으로서의 역할을 하기 때문이다. ${ }^{20)}$ 스피어 핸드북(Sphere Handbook)과 같은 지침서들은 현장 적용이 가능한 기술적이고도 세부적인 기준을 마련해 준다. 그러나 이러한 기술적인 지침서들의 단순 적용이 어렵거나, 구호요원 자신이 지침에 대한 이해가 부족하거나, 즉각 참고가 어려울 경우에는 보다 철학적 이고 원론적인 원칙을 참고할 수 있어야 한다. 인도적 원칙은 급변하는 국제정세와 위기 상황의 파도 속에서 단체가 머물러야 할 지점을 알려주는 “닺줄(anchor)”의 역 할을 하고, 단체의 활동에 어디에 근거하고 있는지를 알려줄 수 있다(Hilhorst \& Schmiemann 2002:494). 또한 현장 활동가들의 주변에서 벌어지는 사건과 사고, 상 호작용(interaction), 환경의 변화들이 어떠한 맥락을 가지고 있으며, 어떠한 의미가 있는지 알려 주는 역할도 한다(Hilhorst \& Schmiemann 2002:494).

제I장

제I장

보다 실질적인 차원에서 인도적 원칙의 준수는 피해지역으로의 안전한 접근을 보 장한다. 특히 중립원칙의 준수는 피해지역 주민들의 신뢰를 확보함으로써 지원 단체 와 개인을 분쟁지역으로 들어갈 수 있게 해 주고, 지원이 필요한 사람에게 접근할 수 있게 해준다(NRC 2012:38; IASC 2010:15). 즉, 인도적 공간을 확보하여 주는 것 이다(장은하 2014b).지역 주민과의 신뢰 구축은 결과적으로 인도적 구호요원들의 안 전과 생명을 보호하여 준다. 접근이 지속적으로 이루어지는 것은 인도적 원칙 준수 를 가능케 하는 선순환적인 구조를 만들어 낸다. 예를 들면 피해지역에 지원물자를 전달하고 전달 상황을 모니터하기 위해 안전하게 상주할 수 있게 됨으로써 수요측정 이 용이해 지고 물자 전용이 최소화됨으로써 결과적으로 공평한 배분을 가능케 하기 때문이다(IASC 2010:16-17).

20) The Advanced Training Program on Humanitarian Action(ATHA) http://www.atha.se/ (검색일: 2015.1.16). 


\section{V. 결론}

본고에서는 인도적 원칙의 유래와 발전과정을 살펴보고 각 원칙에 대한 해설과 분 석을 시도하는 것을 그 목적으로 하였다. 현재 인도적 지원 활동의 근간이 되는 인도, 공평, 중립, 독립의 4 대 원칙은 국제인도법에 그 철학적 기원을 두고 있으며 보다 직 접적으로는 국제적십자운동의 7 개 원칙에서 유래된 것이다. 이는 이 원칙들이 일회성 회의를 통하여 도출된 것이 아닌, 제네바협약과 국제적십자 창설 이후 150 여 년 이라 는 오랜 기간 동안 시행착오와 발전을 거쳐 정립된 개념이라고 할 수 있다. 인도는 인간은 인간 그 자체로서 존엄하다는 인식하에 고통에 처한 사람이 그 어디에서 발견 되든지 도와야 한다는 철학이다. 공평은 차별 없는 지원을 약속하는 것으로써 평등과 공정의 개념을 내포하고 있다. 중립은 대립하는 양 측이 있다는 전제하에 편들지 않 고 지원을 제공하는 것을 의미한다. 독립은 지원 단체가 외부의 어떠한 영향도 받지 않고 자유롭게 결정할 수 있어야 한다는 원칙이다. 그러나 이러한 숭고한 성격에도 불구하고 현재 인도적 원칙은 그적용에 있어서 많은 도전에 직면해 있다.

어쩌면 인도적 원칙은 영원히 도달할 수 없는 이상향일는지도 모른다. 이 원칙들 이 내포하고 있는 속성이 1900년대 후반에 탄생되었던 개념임을 생각해 볼 때, 21세 기의 변화된 국제질서와 분쟁의 양상에서는 적용하기가 쉽지 않을 것이다. 그러나 인도적 지원이라는 명분으로 정치적 개입이 거리낌 없이 자행될수록, 인도적 지원이 라는 명분으로 선진국의 잉여 농산물과 유전자 조작 곡물이 피해국으로 덤핑될수록, 인도적 지원이라는 명분으로 사기업들이 이윤을 추구할수록, 이렇게 그 이름이 무색 할 만큼 인도적이지 않은 인도적 지원이 만연할수록 원칙과 이상에 대한 기준점이 요구된다. 비록 완벽한 실행이 어렵다 할지라도 도달해야할 이상향의 깃발로서, 방향 을 제시해 주는 나침반으로서 인도적 원칙은 필요하며 아직도 유효하다. 


\section{참고문헌}

국제개발협력민간협의회. 2014. "인도주의, 원칙을 실천으로." 2014 인도적지 원 정책포럼 자료집. 서울: 국제개발협력민간협의회.

김성원. 2012. “현대 국제법상 중립법의 실효성에 관한 고찰." 『동아법학』. 56: $389-413$.

대한적십자사. 2010. 『무력충돌 희생자 보호에 관한 제네바협약과 추가의정 서』. 서울: 대한적십자사 인도법연구소.

대한적십자사. 2012. 『국제적십자운동 기본원칙』 . 서울: 대한적십자사 인도 법연구소.

장은하. $2014 \mathrm{a}$. "인도적 지원의 정의에 관한 소고: 국제기구와 공여국 정부의 인도적 지원 개념을 중심으로” 『국제개발협력연구』 . 6(2): 199-243.

장은하. $2014 \mathrm{~b}$. "분쟁지역에서의 인도적 지원: 인도적 공간 사례 연구를 중심 으로”. 『국제개발협력』. 2014 제4호:99-120.

Amar, Francis. 1998. "Is Neutrality Still Possible? Politicization of Humanitarian Aid/Priority Setting in Ethical Dilemmas."

At Conrad N. Hilton Humanitarian Symposium titled Humanitarian Aid Challenges in the New Millenium. http://www. hiltonfoundation.org/images/stories/prize/PDF s/46-pdf1.pdf(검색일: 2014.1.16)

Collinson, Sarah, M. Buchanan-Smith, and S. Elhawary. 2009. "Good humanitarian donorship principles in practice: Assessing humanitarian assistance to internally displaced persons in Sudan and Sri Lanka." London: Humanitarian Policy Group, Overseas Development Institute.

Core Humanitarian Standard(CHS), 2014. "Core Humanitarian Standard on Quality and Accountability." Geneva: HAP International, People In Aid and the Sphere Project. 
CRC. 1994. "Code of Conduct for the International Red Cross and Red Crescent Movement and Non-Governmental Organizations (NGOs) in Disaster Relief."

http://www.icrc.org/eng/assets/files/publications/icrc-002 -1067.pdf(검색일: 2014.1.10)

Edkins, Jenny. 2003. "Humanitarianism, humanity, human." Journal of Human Rights. 2(2): 253-258.

Ferreiro, Marcos. 2012. "Blurring of Lines in Complex Emergencies: Consequences for the Humanitarian Community." http://sites.tufts. edu/jha/archives/1625(검색일: 2015.1.16)

Ferris, Elizabeth G. 2011. "The Politics of Protection: The Limits of Humanitarian Action.” Washington, DC: Brookings Institution Press.

Geremia, Maurizio. 2010. "Neutrality, impartiality and independence in Colombia: an ICRC perspective." Humanitarian Exchange Magazine. 45: 4-6.

Good Humanitarian Donorship. 2003. "23 Principles and Good Practice of Humanitarian Donorship."

http://www.goodhumanitariandonorship.org/gns/principles -good-practice-ghd/overview.aspx(검색일: 2014.4.10)

Gordon, Stuart. 2011. "Winning Hearts and Minds? Examining the Relationship between Aid and Security in Afghanistan's Hlemand Province." Medford/Somerville, MA: Feinstein International Center, Tufts University.

Governance and Social Development Resource Centre(GSDRC). 2015. "Humanitarian Principles and Humanitarian Assistance." http://www.gsdrc.org/go/topic-guides/international-legal -frameworks-for-humanitarian-action/concepts/-principl es-and-legal-provisions/humanitarian-principles-and-hu manitarian-assistance(검색일: 2015.1.16) 
Harmer, Adele, Abby Stoddard, Kate Toth. 2013. “Aid Worker Security Report 2013 - The New Normal: Coping with the kidnapping threat." Washington, DC: USAID.

Harroff-Tavel, Marion. 2003. "Does it still make sense to be neutral?" Humanitarian Exchange. 25: 2-4.

Hilhorst, Dorothea, and Nadja Schmiemann. 2002. "Humanitarian principles and organisational culture: everyday practice in Me decins Sans Fronti res-Holland," Development in Practice. 12(3-4): 490-500.

Hopgood, Stephen. 2008. "Saying No to Wal-Mart? Money and Morality in Professional Humanitarianism." In Michael Barnett and Thomas G. Weiss(eds.). "Humanitarianism in Question."(pp.98-123). Ithaca, New York: Cornell University Press.

HPG and OCHA. 2012. "Responding to natural disasters: Coordination between national armies, regional organisations, and humanitarian actors in the Asia Pacific Region.” Roundtable on Civil-Military Coordination summary note. Bangkok, Thailand, 14 December 2012. http://www.odi.org/sites/odi.org.uk/files/odi-assets/event s-documents/4999.pdf(검색일: 2015.1.16)

Humanitarian Accountability Partnership(HAP). 2010. "Principles of accountability."

http://www. hapinternational.org/pool/files/principles-ofaccountability-and-members-poster-english-jan-2010.pdf (검색일: 2015.1.16)

ICRC. 1986. "Statutes of the International Red Cross and Red Crescent Movement." Adopted by the 25th International Conference of the Red Cross at Geneva in 1986, amended in 1995 and 2006.

https://www.icrc.org/eng/assets/files/other/statutes-en-a 5.pdf(검색일: 2015.1.16) 
Inter-Agency Standing Committee(IASC). 2010. "Workshop for Humanitarian Coordinators: International Humanitarian Norms \& Principles. Guidance Materials." http://www2. wpro. who.int/internet/files/eha/toolkit/web/T echnical\%20References/Coordination/International\%20Huma nitarian\% 20 Norms\% 20 and\%20Principles.pdf(검색일 : 2015.1.16)

IRIN. 2013. "Humanitarian News and Analysis: The Use and Abuse of Humanitarian Principle."

http://www.irinnews. org/fr/report/97502/the-use-and-ab use-of-humanitarian-principle(검색일: 2015.1.16)

Leader, Nicholas. 2000. "The Politics of Principle: the principles of humanitarian action in practice." London: Humanitarian Policy Group, Overseas Development Institute.

Mackintosh, Kate. 2000. "The Principles of Humanitarian Action in International Humanitarian Law. Study 4 in: The Politics of Principle: the principles of humanitarian action in practice." London: Humanitarian Policy Group, Overseas Development Institute.

McGoldrick, Claudia. 2011. "The future of humanitarian action: an ICRC perspective." International Review of the Red Cross. 93(884): 965-991.

Nickolls, Jo. 2003. "Limits to Neutrality in Iraq." Humanitarian Exchange Magazine. 25: 7-9.

Norwegian Refugee Council(NRC). 2012. "Humanitarian Principles: Q \& A." Perspective: Humanitarian and International Affairs Magazine. 2012(4): 38-39.

Overseas Development Institute(ODI). 2007. "Humanitarian advocacy in Darfur: the challenge of neutrality." Humanitarian Policy Group Policy Brief. 28: 1-7.

People In Aid. 2003. "Code of good practice: In the management and support of aid personnel." London: People in Aid. 
Pictet, Jean. 1979. "The fundamental principles of the Red Cross." International Review of the Red Cross. 19(210): 130-149.

Plattner, Denise. 1996. "ICRC neutrality and neutrality in humanitarian assistance." International Review of the Red Cross. 36(311): 161-180.

Rieff, David. 2003. "A bed for the night: Humanitarianism in crisis." New York City: Simon and Schuster.

Rieffer-Flanagan, Barbara Ann. 2009. "Is Neutral Humanitarianism Dead? Red Cross Neutrality: Walking the Tightrope of Neutral Humanitarianism." Human Rights Quarterly. 31(4): 888-915.

Rasmussen, Anders Fogh. 2010. Speech: NATO Secretary General Rasmussen, Anders Fogh Strategic Concept Seminar in Helsinki, 2010.

http://www.nato.int/cps/en/natolive/opinions_61891.htm(검 색일: 2015.1.20)

Slim, Hugo and Emanuela-Chiara Gillard. 2013. "Ethical and legal perspective on cross-border humanitarian operations." Humanitarian Exchange Magazine 59: 6-8.

Sphere Project. 2011. "The Sphere Handbook: Humanitarian Charter and Minimum Standards in Humanitarian Response.” Warwickshire: Practical Action Publishing.

Stoddard, Abby. 2003. "With Us or Against Us? NGO Neutrality on the Line." Humanitarian Exchange Magazine. 25: 5-7.

Gordon, Stuart. 2011. "Winning Hearts and Minds? Examining the Relationship between Aid and Security in Afghanistan's Helmand Province." Feinstein International Center, Tufts University.

Terry, Fiona. 2011. "The International Committee of the Red Cross in Afghanistan: reasserting the neutrality of humanitarian action." International Review of Red Cross. 93(881): $173-188$. 
The Advanced Training Program on Humanitarian Action(ATHA). 2014. "Humanitarian Principles" http://www. atha. se/content/humanitarian-principles-0(검 색일: 2015.1.16.)

Udombana, Nsongurua J. 2005. "When neutrality is a sin: the Darfur crisis and the crisis of humanitarian intervention in Sudan.” Human Rights Quarterly. 27(4): 1149-1199.

UN OCHA. 2012. "OCHA on Message: Humanitarian Principles." https://ochanet. unocha. org/p/Documents/OOM-humanitari anprinciples_eng_June12.pdf(검색일: 2015.1.16)

UN. 1991. "Strengthening of the coordination of humanitarian emergency assistance of the United Nations." General Assembly Resolution 46/182. New York: UN.

UN. 2004. "Strengthening of the coordination of emergency humanitarian assistance of the United Nations." General Assembly Resolution 58/114. New York: UN.

UNHCR. 1950. "The Statute of the Office of the United Nations High Commissioner for Refugees."General Assembly Resolution 428(V) of 14 December 1950. Geneva: UNHCR.

Vagts, Detlev F. 1998. "The Traditional Legal Concept of Neutrality in a Changing Environment." American University International Law Review. 14(1): 83-102.

Vaux, Anthony, and Tony Vaux. 2001. "The selfish altruist: relief work in famine and war." London: Earthscan Publications.

Walker, Peter and Daniel Maxwell. 2008. "Shaping the humanitarian world." Routledge: London and New York.

Walker, Peter. 2004. "What Does it Mean to be a Professional Humanitarian?" http://sites.tufts. edu/jha/archives/73(검색 일 2014. 1. 24).

Weller, Marc. 1997. "The Relativity of Humanitarian Neutrality and Impartiality." https://sites. tufts. edu/jha/archives/119(검색 일: 2014.1.10) 
Wortel, Eva. 2009. "Humanitarians and their moral stance in war: the underlying values." International Review of the Red Cross. 92(876): 779-802.

\section{- Websites}

Core Humanitarian Standard http://www. corehumanitarianstandard.org/ Good Humanitarian Donorship(GHD) http://www.goodhumanitariandonorship.org Governance and Social Development Resource Centre(GSDRC) www.gsdrc.org/ HAP International www.hapinternational.org/ IFRC website http://www.ifrc.org/

The Advanced Training Program on Humanitarian Action(ATHA) http://www.atha.se/

UN OCHA www.unocha.org/ 